\title{
Social Presence Reconsidered: Moving Beyond, Going Back, or Killing Social
}

\section{Presence}

Murat Öztok

Department of Educational Research, Lancaster University, Lancaster, United Kingdom

Benjamin Kehrwald

Teaching Innovation Unit, University of South Australia, Adelaide, South Autralia 


\section{Social Presence Reconsidered: Moving Beyond, Going Back, or Killing Social}

\section{Presence}

Online education research has long employed the concept of social presence to study interactions in technologically-mediated spaces. Yet, a precise shared definition of social presence does not exist. There is a lack of clarity around this term and conflation with other phenomena. As researchers and practitioners striving for clarity, do we need such a heavily burdened and deeply ambiguous term? To support the development of clarity and provide a way forward with current conversations about social presence, this article traces how the concept of social presence has been developed and appropriated in the online and distance education literature. We do not simply focus on the historical trajectory of the concept but discuss how it is utilized to address the growing complexities of social interactions in parallel to the increasing affordances of new technologies. Our aim is to illustrate that social presence is over extended and widely stretched to correspond with the possibilities of socialization and that it has long lost its depth and breadth, and thus, its analytical strength. We argue that we should focus more on the relative salience of interpersonal relationships if we are to understand the relational aspects of being online.

Keywords: social presence, online education, online communication, computer-mediated communication, being online

\section{Introduction}

"Social Presence" is a vernacular concept in the field of online education, utilized to cover a wide range of social phenomena in online spaces. What it is, what it does, how it is perceived, and its effects have been debated - and often used interchangeably - for the past six decades (Oztok \& Brett, 2011). Indeed, "it is often hard to distinguish between whether someone is talking about 
KILLING SOCIAL PRESENCE

social interaction, immediacy, intimacy, emotion, and/or connectedness when they talk about social presence" (Lowenthal, 2010, p. 125). However, conceptualizing all forms of beings, all types of affinities, all range of emotions and/or feelings, and all degrees of connectedness under the umbrella of social presence jeopardizes its analytic rigor: it explains nothing at all. Inflating its analytical capacity inevitably decreases its theoretical and practical value.

Is it now time to 'kill' social presence; to do away with the term and find a term or terms which provide the necessary vocabulary for a rigorous study of the phenomena in question and inform online education practice in a more definitive way? This conceptual article argues the radical position that social presence has been repeatedly appropriated and stretched beyond its limit, and thus it has lost its meaning. A more rigorous treatment of the social phenomena currently described under the umbrella of social presence is needed in order to understand the complexities of technology-mediated social processes.

\section{Social Presence}

Social presence was defined by media studies scholars to examine people's attitudes toward different communication media. The zeitgeist was that of McLuhanism and the underlying argument was that of the medium itself: a medium capable of conveying social cues promotes communication - an idea later described as 'media richness'. To define the richness of a medium, Short, Williams, and Christie (1976) coined the concept:

We believe, however, that the degree of salience of the other person in the interaction and the consequent salience of the interpersonal relationships is an important hypothetical construct that can usefully be applied more generally. We shall term this quality 'social presence'. ... We regard social presence as being a quality of the communications medium [emphasis added]. Although we would expect it to affect the way individuals 
KILLING SOCIAL PRESENCE

perceive their discussions, and their relationships to the persons with whom they are communicating, it is important to emphasize that we are defining social presence as a quality of the medium itself. (p. 65)

Putting too much emphasis on the capacity of the communication medium (perhaps because the medium is the message ${ }^{1}$ was the zeitgeist), Short et al. (1976) suggested what it means to be with others is a critical attribute of a medium. However, it is not clear from their definition whether it is the characteristics of the media that determine communication differences or whether users' perceptions of media alter their behavior (Walther, 1992). We argue that this lack of clarity caused two misconceptions: (1) social presence, as a socio-psychological perception, is mistaken for a capacity of media, and (2) social presence, as a concept, is mistaken as the effects it has upon the social fabric of mediated spaces. This confusion prevails.

Online education research regards social presence as the degree to which individuals represent themselves (Rourke, Anderson, Garrison, \& Archer, 1999) and perceive others in mediated spaces (Biocca, Harms, \& Burgoon, 2003). In order to characterize how the concept reflects the aforementioned confusions, we borrow the argument that online education scholars appropriated social presence through three eras over time (Oztok \& Brett, 2011): (1) A research era that conceptualized social presence as a property of a medium (e.g., Mason, 1994; McLeod, Baron, Marti, \& Yoon, 1997); (2) A research era that conceptualized social presence as the behaviors and/or attitudes of the individuals (e.g., Gunawardena, 1995; Tu \& McIsaac, 2002); and (3) A research era that conceptualized social presence as a facilitating element (e.g., Picciano, 2002; Rogers \& Lea, 2005). It is important to note that we do not assume these eras are successive in their own terms, neither do we regard them clearly distinct from each other. We

\footnotetext{
1 "The medium is the message" is a phrase coined by Marshall McLuhan (see, McLuhan, 1964), meaning that the type of a communication medium creates a symbiotic relationship by which the medium influences how the message is perceived.
} 
KILLING SOCIAL PRESENCE

accept these eras as illustrating how social presence is over extended and widely stretched to correspond with the possibilities of technology-mediated socialization. In each of these eras, researchers either focused on communicative actions impinging on the social presence or the effects of social presence on teaching/learning, leaving the core concept rather under addressed: being with others in an online space.

We argue that the original definition should be re-asserted. We should focus more on the relative salience of interpersonal relationships if we are to understand the relational aspects of being online. For example, as articulated by Walther (1992), Tu and McIsaac (2002), Kehrwald (2008), social presence, as an antecedent of interpersonal interaction, is a critical feature of learning processes which are premised upon the modification of ideas that results from interpersonal communication. In this transactional (Shin, 2010), interactivist (Bickhard, 1992) or relational (Lave \& Wenger, 1991) view of learning, meaning is made not only in the context of communicative exchanges, but in the context of the relations between them (Oztok, 2016). Further, we argue that to fully understand relational aspects of being online, we must agree upon a clear definition of social presence by distinguishing it from related phenomena, as well as from its effects and its use. In order to do so, researchers should avoid interchangeably using social presence to describe both what social presence is and what social presence does, including supporting the operation of social-relational mechanisms such as trust or respect, social processes such as collaborative learning or social phenomena that influence user behaviors in online environments. Such an amalgam of what social presence is and what it does devaluates its meaning to the extent that an analytical work cannot be performed: Complex social life in online spaces is left undifferentiated, and thus unexplained. 
KILLING SOCIAL PRESENCE

\section{Applications of Social Presence}

As the concept of social presence has been applied or redefined to address the growing complexities of social interactions in parallel to the increasing affordances of new technologies, researchers took a step away from its original purpose. Time and again, the differences between what social presence is and what it does have been blurred. The following four applications of the term social presence in the literature of online education exemplify the resulting lack of clarity in understanding social presence.

\section{Social presence as the ultimate social fabric}

Influenced by McLuhanism, a key idea of this research approach is that the sense of social presence creates and supports ongoing interaction in online spaces (e.g., Hiltz \& Turoff, 1993; McComb, 1994; Riva, 2002). Although the connection with the McLuhanism became subtle, research concerning the Community of Inquiry ${ }^{2}$ appropriated this approach and regarded social presence as the ultimate factor for deep and meaningful social interactions in online spaces (see Garrison et al., 1999). However, this seems to have been extrapolated beyond support to suggest that social presence is responsible for all interpersonal engagements or knowledge sharing in technology-mediated spaces. We argue that social presence is necessary but not sufficient. Further, social presence and knowledge sharing or engagements are related but different phenomena; thus, it is not clear why social presence is needed to explain knowledge sharing or social engagements.

\section{Social presence as a category of identity (self-performance / self-narrative)}

Some researchers regarded social presence as projection of identities in online spaces (Tu \& McIsaac, 2002) (also, see research concerning social presence using the Community of Inquiry

\footnotetext{
${ }^{2}$ Due to space limitations, we cannot provide a full account on the Community of Inquiry framework here. For more information, please see (Garrison, Anderson, \& Archer, 1999; Rourke et al., 1999).
} 
KILLING SOCIAL PRESENCE

framework), arguing that when students participate in activities, they project their own identities into cyberspace, and, conversely "feel the presence of others online" (Gunawardena \& Zittle, 1997, p. 11). We acknowledge that social presence, by and large, is related with enactments of self; yet, it is important here not to conflate social presence and the communicative cues with the concept of identity itself. The concept of identity in online spaces had been discussed widely, but it is important to maintain a clear distinction between social presence, which is focused on a subjective experience in technology-mediated situations, and identity, which is variously defined in sociology, psychology and other disciplines in ways that are not superseded by descriptions of social presence provided by scholars of online education.

\section{Social presence as a collective phenomenon (sense of community / sense of connectedness)}

Researchers regarded social presence as "a measure of the feeling of community that a learner experiences in an online environment” (Tu \& McIsaac, 2002, p. 131), arguing that social presence is "the degree to which participants in computer-mediated communication feel affectively connected one to another" (Swan \& Shih, 2005, p. 115). In Short et al's (1976) original definition, there was no focus on the collective, merely on the fact that an 'other' (or others) were perceived as 'real' (as salient social actors) and 'there' in the technology mediated situation. This is potentially a case where the effects of social presence (i.e. what it does) are being conflated with what social presence 'is'. Specifically, social presence creates the possibility of social interaction and social processes owing to the presence of a socially salient other (in spite of a lack of physical presence), but those possibilities are distinct from what it is, i.e., the experience of another as both 'real' and 'there' (see Lowenthal \& Dunlap, 2014). It is important to acknowledge the role of social presence in as an antecedent to technology mediated social processes and the role it may have in reducing the social and psychological distance experienced by individuals who are engaged in technology-mediate social activity, but it is 
KILLING SOCIAL PRESENCE

important to maintain clarity about the point that not all of the social phenomena that individuals experience in technology mediated situations are 'social presence', per se.

\section{Social presence as the capacity of communication medium}

Researchers have argued that social presence produces the experience of seemingly accurate representations of objects, events, and people: a mediated experience that looks, sounds, and feels like truly natural and real; one that seems very much like it is not mediated (Lombard \& Ditton, 2006). Nevertheless, the original definition clearly suggests some level of psychological involvement by referring to "the degree of salience of the other person in the interaction and the consequent salience of the interpersonal relationships" (Short et al., 1976, p. 65). The distinction here is about the influence of media on social presence. We argue that being perceived as a quality of media, social presence, as a psychological phenomenon, is influenced by, but not dependent upon media characteristics. Social presence research on user experiences clearly demonstrates that individuals experience instances of both 'high' and 'low' degrees of social presence in so-called 'rich' and 'lean' media and that those experiences are influenced by others' projection of presence as well as the subjects' ability to perceive and interpret social presence cues.

We do not argue that social presence research is uninteresting or incomprehensive. Rather, the suggestion that the aforementioned phenomena are social presence is confusing. In some cases, such as identity, intimacy, and connectedness, there is an established nomenclature from disciplines such as sociology and psychology which describes the same phenomena in nontechnologically-mediated contexts. We argue that it is theoretically inadequate and practically unproductive to stretch the meaning of social presence to explain a phenomenon that has already been well explored in other fields. 
KILLING SOCIAL PRESENCE

\section{Discussion}

Do we need a heavily burdened and deeply ambiguous term? No, we do not! To be clear, we argue the concept of social presence is necessary. However, it needs to be more rigorously defined and differentiated from other concepts or phenomena. For us, social presence should mean only one thing, and the effects or applications of it should be studied using more appropriate and productive terms.

Social presence is a concept that is essential to the consideration of technology-mediated social processes; without it, some of these processes cannot be analyzed and understood. Yet, the question remains: What exactly is social presence? Further to that, how can research document its effects and applications without a clear definition of social presence? Surely, developing "a systematic theory will in turn enable development of appropriate measures of social presence" (Biocca et al., 2003, p. 457). Thus, we want this manuscript to be an open call for scholars to challenge the existing notions that blurs the theoretical and practical use of the concept.

Here, we try to do our bit by reconsidering the rather understudied idea in Short et al.'s (1976) original definition: the relative salience of others. We define social presence as the subjective feeling of being with other salient social actors in a technologically-mediated space. It is the sense of 'being there, together' when 'being there' does not involve a physical presence. This definition is predicated on the sense that there is an 'other' (or others) in the technologymediated space and that the others are potentially viable partners for social interaction. We believe this definition is fruitful because it underscores the inter-subjective nature of social presence: It is constructed dialogically and is a combination of the self and others (Kehrwald, 2010; Oztok, 2013). 
KILLING SOCIAL PRESENCE

\section{Conclusion}

Online education has long employed the concept of social presence to study communicative actions in technologically-mediated spaces. Yet, what social presence is unclear. The appropriation of the term 'social presence' and its application to a variety of technologymediated communicative situation, most notably the Community of Inquiry framework (Garrison et al., 1999), have done a disservice to efforts to understanding social presence. It may be now time to kill the social presence we created for the sake of the conceptual clarity required for social analysis.

However, we do not want to kill the concept of social presence yet. This action would not only render the research obsolete and leave us without a vocabulary to explain social phenomena in technology-mediated spaces but also would be unfair to the concept of social presence. Thus, we are left with three choices. First, as scholars of online education, we can return to the original definition and be loyal to its socio-psychological limits and vigilant about the uses and limits of that definition. If we go back to the original definition of what social presence is, we can differentiate it from what it does and more rigorously explore the role it plays in teaching and learning activities in online spaces. This will give us a stronger arsenal to better conceptualize the dynamic nature of the relative salience of others. Second, we can come up with new terminology to better describe the complex social phenomena that are evident in technologymediated social systems. New terminology can thoroughly capture the current applications and trends in theory and practice of online education and thus provide opportunities to better connect theory with practice. Third, we can continue to produce accounts to be recycled since they cannot address the complexities of being online. 
This article is unfortunately too short to discuss these three options in detail; however, our aim is to steer away the online education research from heading to the third option. We advocate an agenda which (1) acknowledges the first option, with a focus on the presence of other salient social actors in mediated situations and (2) seeks to clarify and extend our understanding of social presence by not only promoting shared understandings of what it is, and what it does to facilitate and support technology-mediated social activity. We hope this article will spark a long needed discussion about social presence and being online.

\section{Notes on contributors}

Murat $\ddot{\text { Oztok }}$ My research interests concern collaborative work and group discussion in digitallymediated environments, with a theoretical and practical commitment to social justice and equity within learning communities. I draw upon Marxist and Post-Colonial perspectives, and explore the manifestations of social, historical, political, and economic Discourses in digitally-mediated environments. In particular, I am interested in understanding the ways that sociocultural elements inherent in applications of digital education operate to marginalize students who fall outside the ideations of dominant ideology.

Benjamin Kehrwald is a specialist in online learning in higher education. He is an experienced researched and practitioner with over 20 years experience using technology in education. He is currently part of the Teaching Innovation Unit at the University of South Australia.

\section{References}


KILLING SOCIAL PRESENCE

Bickhard, M. H. (1992). How does the environment affect the person? In L. T. Winegar \& J. Valsiner (Eds.), Children's development in social context (pp. 33-52). Mahwah, NJ: Lawrence Erlbaum.

Biocca, F., Harms, C., \& Burgoon, J. K. (2003). Toward a more robust theory and measure of social presence: Review and suggested criteria. Presence: Teleoperators and Virtual Environments, 12(5), 456-480. doi:10.1162/105474603322761270

Garrison, D. R., Anderson, T., \& Archer, W. (1999). Critical inquiry in a text-based environment: Computer conferencing in higher education. The Internet and Higher Education, 2(2-3), 87-105. doi:10.1016/s1096-7516(00)00016-6

Gunawardena, C. N. (1995). Social presence theory and implications for interaction and collaborative learning in computer conferences. International Journal of Educational Telecommunications, 1(2/3), 147-166.

Gunawardena, C. N., \& Zittle, F. J. (1997). Social presence as a predictor of satisfaction within a computer-mediated conferencing environment. American Journal of Distance Education, 11(3), 8-26. doi:10.1080/08923649709526970

Hiltz, S. R., \& Turoff, M. (1993). The network nation: Human communication via computer. Cambridge, MA: MIT Press.

Kehrwald, B. (2008). Understanding social presence in text-based online learning environments. Distance Education, 29(1), 89-106. doi:10.1080/01587910802004860

Kehrwald, B. (2010). Being online: Social presence as subjectivity in online learning. London Review of Education, 8(1), 39-50. doi:10.1080/14748460903557688

Lave, J., \& Wenger, E. (1991). Situated learning: Legitimate peripheral participation. New York, NY: Cambridge University Press. 
KILLING SOCIAL PRESENCE

Lombard, M., \& Ditton, T. (2006). At the heart of it all: The concept of presence. Journal of Computer-Mediated Communication, 3(2). doi:10.1111/j.1083-6101.1997.tb00072.x

Lowenthal, P. R. (2010). The evolution and influence of social presence theory on online learning. In T. T. Kidd (Ed.), Online education and adult learning: New frontiers for teaching practices (pp. 124-139). Hershey, PA: IGI Global.

Lowenthal, P. R., \& Dunlap, J. C. (2014). Problems measuring social presence in a Community of Inquiry. E-Learning and Digital Media, 11(1), 19-30. doi:10.2304/elea.2014.11.1.19

Mason, R. (1994). Using communications media in open and flexible learning. London, UK: Kogan Page.

McComb, M. (1994). Benefits of computer-mediated communication in college courses. Communication Education, 43(2), 159-170. doi:10.1080/03634529409378973

McLeod, P. L., Baron, R. S., Marti, M. W., \& Yoon, K. (1997). The eyes have it: Minority influence in face-to-face and computer-mediated group discussion. Journal of Applied Psychology, 82(5), 706-718. doi:10.1037/0021-9010.82.5.706

McLuhan, M. (1964). Understanding media: The extensions of man. New York, NY: McGrawHill.

Oztok, M. (2013). Tacit knowledge in online learning: community, identity, and social capital. Technology, Pedagogy and Education, 22(1), 21-36. doi:10.1080/1475939x.2012.720414

Oztok, M. (2016). Cultural ways of constructing knowledge: The role of identities in online group discussions. International Journal of Computer-Supported Collaborative Learning, 11(2), 157-186. doi:10.1007/s11412-016-9233-7 
KILLING SOCIAL PRESENCE

Oztok, M., \& Brett, C. (2011). Social presence and online Learning: A review of research. The Journal of Distance Education, 25(3). Retrieved from http://www.ijede.ca/index.php/jde/article/view/758/1299

Picciano, A. G. (2002). Beyond student perceptions: Issues of interaction, presence, and performance in an online course. Journal of Asynchronous Learning Networks, 6(1), 2140.

Riva, G. (2002). The sociocognitive psychology of computer-mediated communication: The present and future of technology-based interactions. CyberPsychology \& Behavior, 5(6), 581-598. doi:10.1089/109493102321018222

Rogers, P., \& Lea, M. (2005). Social presence in distributed group environments: The role of social identity. Behaviour \& Information Technology, 24(2), 151-158. doi:10.1080/01449290410001723472

Rourke, L., Anderson, T., Garrison, D. R., \& Archer, W. (1999). Assessing social presence in asynchronous text-based computer conferencing. Journal of Distance Education, 14(2), $50-71$.

Shin, N. (2010). Beyond interaction: The relational construct of 'Transactional Presence'. Open Learning: The Journal of Open, Distance and e-Learning, 17(2), 121-137. doi:10.1080/02680510220146887

Short, J., Williams, E., \& Christie, B. (1976). The Social Psychology of Telecommunications. London, UK: Wiley.

Swan, K., \& Shih, L. F. (2005). On the nature and development of social presence in online course discussions. Journal of Asynchronous Learning Networks, 9(3), 115-136. 
Tu, C.-H., \& McIsaac, M. (2002). The relationship of social presence and interaction in online classes. American Journal of Distance Education, 16(3), 131-150. doi:10.1207/s15389286ajde1603_2

Walther, J. B. (1992). Interpersonal effects in computer-mediated interaction: A relational perspective. Communication Research, 19(1), 52-90. doi:10.1177/009365092019001003 